\title{
Constrains for seeking post-abortion care among adolescents and young women in Guangzhou, China: a cross-sectional study
}

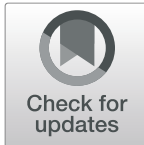

\author{
Yiding Wang ${ }^{1}$, Jinzhi Liu', Ribo Xiong ${ }^{2^{*}}$ and Yan Liu'
}

\begin{abstract}
Background: In China, post-abortion care (PAC) services mainly focus on married couples, such that adolescents and unmarried young women have limited access to those services for contraception counseling. The provision of youthfriendly PAC services in public hospitals is a new concept in China. This study examined the magnitude of PAC services utilization as well as factors influencing its uptake among adolescents and young women in Guangzhou, China.

Methods: A cross-sectional study was performed from 1st March 2020 to 30th September 2020 using an anonymous self-administered questionnaire among 688 women aged 15-24 years in Tianhe district, Guangzhou. The Multivariate logistic regression was used to determine factors that were significantly associated with the uptake of PAC services.

Results: The magnitude of PAC services utilization was 35.9\% among adolescents and young women in Guangzhou, China. Students were 69.0\% significantly less likely to use PAC services compared to women who had no job. Immigrants were $59.0 \%$ significantly less likely to use PAC services than their native counterparts. Women who had a feeling of stigma were $70.0 \%$ significantly less likely to use PAC services compared to those who did not feel stigmatized.

Conclusions: The study highlights the need to strengthen youth-friendly PAC services provision, and emphasizes the importance of education about both family planning and abortion services among disadvantaged subgroups of women in the study setting.
\end{abstract}

Keywords: Abortion, Post-abortion care, Utilization, Stigma, Adolescents, Young women, China

\section{Background}

High abortion rates among sexually active youth in China is a serious public health concern central to government policy on tackling reproductive health [1]. The large proportion of unintended pregnancies and subsequent induced abortions in this age group is driven, in their limited knowledge about reproduction and contraception, as well as a lack of access to family planning services [2]. Data published by China's National Health and Family

\footnotetext{
* Correspondence: xiongribo@outlook.com; 19714343@qq.com

${ }^{2}$ Department of rehabilitation, Nanhai Hospital, Southern Medical University, Foshan, China

${ }^{1}$ Department of gynecology \&obstetrics, The Third Affiliated Hospital of Southern Medical University, Guangzhou, China
}

Planning Commission indicates that almost half of the abortions were conducted on women below the age of 25 [1]. It's difficult to fully ascertain the number of adolescents and youth nationwide who have experienced abortion procedures before the age of 25 even though abortion is legal and available in China. Evidence also suggests that pregnancy termination is likely to cause long-lasting physical and psycho-social reactions for women who seek them [3]. This is especially true for the relatively mentally immature group of younger youth aged 15-18 years, who do not always possess the understanding, skills or support to deal with clinical and social consequences. 
To address the complications related to abortions, post-abortion care (PAC) has been introduced to break the cycle of unwanted pregnancy and improve women's sexual and reproductive health. Standard PAC includes contraceptive counseling and contraceptive methods provision; emergency care; human immunodeficiency virus counseling; and community empowerment [4]. Prior studies in China have demonstrated that PAC utilization was directly related to marital status, knowledge of fertility return after abortion, decision-making on having a child, and service providers' perspectives [5, 6]. However, most of the participants recruited in these studies were women without any restrictions or young unmarried women. Further, PAC services in China mainly focus on married couples, which means young girls have limited access to these services. Youth-friendly family planning counseling is not explicitly fostered in the current context or included in standard counseling approaches. Although PAC within public abortion clinics is provided free of charge, the implication is that young people encounter more obstacles towards acquiring PAC compared with older adults, resulting in the low rate of contraception use and subsequent repeat abortions. How the specific context affects the implementation of PAC and what efforts are needed to address the barriers to PAC services among this population continuously attract researcher's interests.

The World Health Organization identifies differences in the needs of young people (from 15 to 24 years old) as PAC service clients and recommends specific guidelines that maximize protection against unintended pregnancy [4]. China offers an interesting context for understanding PAC utilization and its associated factors among adolescents and young women. In 2017, the Chinese government launched a Medium-and LongTerm Development Program for young people (14-35 years) to strengthen the popularization of sexual knowledge and implement sexual health education [5]. Guangzhou, where this study was conducted, was one of the pilot cities where youth-friendly family planning was included in standard counseling to address young people's specific concerns and needs. A non-judgemental stance in counseling was also developed to discuss their ambivalent attitudes towards sexuality. Yet the extent to which PAC services are utilized and its contributing factors in such settings are not well-understood. In addition, in the past decade, China has experienced dramatic social changes with young people rushing to costal developed regions such as Shanghai and Guangzhou to seek better livelihood. Previous studies have reported immigrant women were less likely to use PAC services $[6,7]$. However, little is known on the factors determining their seeking PAC services, especially young immigrant women who may delay the request for termination and subsequent family planning counseling to forestall stigmatization. This is a limitation given the changing demographics of young abortion patients in this area. This study aims to assess PAC utilization among adolescents and young women, and explore the potential factors influencing its uptake in Guangzhou, China.

\section{Methods}

Guangzhou is an economically developed city in south China and is one of the largest metropolitans. Tianhe district, where this study was conducted, was the site where youth-friendly PAC services were pilotly provided in public hospitals. This district has the largest migrant population and college students in Guangzhou.

This was a cross-sectional study conducted in Tianhe district between March and September in 2020. We recruited women 1) at an age between 15 and 24 years; 2) having experienced at least once induced abortions; 3) providing informed consent. Women who had a history of psychiatric disorder or returned incomplete questionnaires were excluded.

Based on sample size estimation, 568 women were needed where effect size was set at $0.5, \alpha=0.05$ referring to the study of Tang et al. [7] Considering a nonresponse rate of $20.0 \%$, we aimed to recruit 682 women. A total of 813 eligible women were invited to participate; 122 women refused to be enrolled in and 3 women returned incomplete questionnaires, resulting 688 women. This study included 688 adolescents and young women allowing detection of significant differences with a power of 0.85 calculated by Gpower software.

Four public hospitals that provided the youth-friendly PAC pilotly were included in the study. The number of participants from each hospital was determined based on population proportion to size. The number of participants was 235, 76, 201 and 176 from the first, second, third and fourth hospital respectively.

An anonymous self-administered questionnaire was used and completed by participants. The questionnaire was comprised of four sections:(1) general sociodemographic information, such as age, education, occupation, marital status, average monthly income and migration status; (2) reproductive history, such as parity, previous induced abortion and number of living children; (3) contraceptive practices, such as contraceptive knowledge and contraceptive use during the six months preceding survey; (4) social factors, such as a feeling of stigma, other people's (e.g partner, husband, parents) attitudes towards contraceptive use, person who determine the utilization of PAC services, fear that contraceptives are harmful and negative attitudes towards PAC services.

All the participants were assured confidentiality of their identity and responses before the survey. Small gifts 
(sanitary towel) were given to them when they returned the questionnaire. Data was collected by four female nurses/midwives with field research experience who were trained by the principal investigator for two days.

Ethics approval was obtained from Ethical Committee of Southern Medical University. Participants were asked to sign a consent form prior to the study. For participants under 18 years old, written informed consent was obtained from her parent or guardian.

Data was analyzed using SPSS16.0. Cross-tabulations with Chi-square test were used evaluate the significance of differences between abortion patients who utilized PAC services and those who did not. Then the independent variables that were significantly associated $(P<0.05)$ with the uptake of PAC services were considered as possible contributing factors and entered into a multivariate logistic regression model. Odds ratios (ORs) with 95\% confidence intervals $(95 \% \mathrm{CI})$ were calculated to measure the strength of association. A $P$ value $<0.05$ was considered significant in the analysis.

\section{Results}

Of the 688 abortion patients who were enrolled in this study, 247 utilized PAC services, thus resulting a magnitude of $35.9 \%$.

$86.3 \%$ of the participants were aged between 19 and 24 years and less than one fifth (13.7\%) were adolescents. A majority (44.9\%) of the participants had college level education or more. More than half $(69.0 \%)$ of the participants were unmarried. Regarding occupation, $46.9 \%$ of the participants were students. The highest proportion (46.2\%) of participants earned between 1000 and 4000 Chinese yuan per month, followed by those who earned less than 1000 Chinese yuan (29.7\%). Distribution by migration status shows that $64.8 \%$ of the participants were immigrants. (Table 1)

The proportion of PAC utilization was significantly lower among students (29.1\%) than among clerical staff/ worker (40.0\%), technician (44.4\%) and jobless (73.3\%). The proportion of immigrants that used the services was almost two times lower than that of non-immigrants (26.0 and $54.1 \%$ respectively). (Table 2 ). In addition, the proportion that used the services was significantly higher among women who did not feel stigmatized (70.2\%)than among those who had a feeling of stigma $(21.1 \%)$ or those who were uncertain (12.2\%). (Table 5). However, there were no statistically significant variations in the proportions of PAC services utilization by other factors considered. (Tables 2, 3, and 4).

Table 6 showed the factors associated with PAC utilization among adolescents and young women in the study site. Students were $69 \%$ significantly less likely to use PAC services compared to women who had no job $(\mathrm{OR}=0.308, \quad 95 \% \mathrm{CI}=0.129 \sim 0.453) . \quad$ Similarly,
Table 1 Socio-demographic features of abortion patients

\begin{tabular}{|c|c|c|}
\hline Variables & Frequency & Percentage (\%) \\
\hline \multicolumn{3}{|l|}{ Age } \\
\hline $15 \sim 18$ & 94 & 13.7 \\
\hline $19 \sim 24$ & 594 & 86.3 \\
\hline \multicolumn{3}{|l|}{ Marital status } \\
\hline Married & 213 & 69.0 \\
\hline Not married & 475 & 31.0 \\
\hline \multicolumn{3}{|l|}{ Level of education } \\
\hline Junior high school or less & 178 & 25.9 \\
\hline Senior high school & 201 & 29.2 \\
\hline College or more & 309 & 44.9 \\
\hline \multicolumn{3}{|l|}{ Occupation } \\
\hline Jobless & 45 & 6.5 \\
\hline Student & 323 & 46.9 \\
\hline Technician & 27 & 3.9 \\
\hline Clerical staff/worker & 159 & 23.1 \\
\hline Self-employed & 134 & 19.5 \\
\hline \multicolumn{3}{|l|}{ Average monthly income } \\
\hline$<1000 \mathrm{CNY}$ & 204 & 29.7 \\
\hline $1000 \sim 4000 \mathrm{CNY}$ & 318 & 46.2 \\
\hline$>4000 \mathrm{CNY}$ & 166 & 24.1 \\
\hline \multicolumn{3}{|l|}{ Migration status } \\
\hline Non-migrant & 242 & 35.2 \\
\hline Immigrant & 446 & 64.8 \\
\hline
\end{tabular}

CNY: Chinese Yuan

Immigrant: individuals who do not have permanent resident certificate and be living over a month in Guangzhou

immigrant women were $59 \%$ less likely to receive PAC services compared to native women $(\mathrm{OR}=0.409$, $95 \% \mathrm{CI}=0.137 \sim 0.620$ ). The likelihood of using PAC services was also varied by whether women had a feeling of stigma. Women who had a feeling of stigma were $70 \%$ significantly less likely to use PAC services compared to those who did not feel stigmatized $(\mathrm{OR}=0.296,95 \% \mathrm{CI}=$ $0.104 \sim 0.378)$.

\section{Discussion}

We conducted a study aimed at determining the proportion of adolescents and young women who used PAC services and possible factors associated with its uptake. To our knowledge, this was one of the first studies with respect to the utilization of PAC services among adolescents and young women. Almost all existing studies in China were conducted among women without restrictions or the young unmarried women.

In this study, a minority of the participants, 247 (35.9\%), used PAC services before they leave the facility. The uptake of PAC services among adolescents and young women in the study setting was lower than the 
Table 2 Variations in the use of PAC services by socio-demographic features

\begin{tabular}{|c|c|c|c|c|c|}
\hline \multirow[t]{2}{*}{ Characteristics } & \multirow[t]{2}{*}{ Total } & \multicolumn{2}{|c|}{ Use of PAC services } & \multirow[t]{2}{*}{$x^{2}$} & \multirow[t]{2}{*}{$P$} \\
\hline & & Frequency & Percentage(\%) & & \\
\hline Marital status & & & & 0.668 & 0.363 \\
\hline Married & 213 & 79 & 37.1 & & \\
\hline Not married & 475 & 168 & 35.3 & & \\
\hline Level of education & & & & 1.614 & 0.446 \\
\hline Junior high school or less & 178 & 57 & 32.0 & & \\
\hline Senior high school & 201 & 76 & 37.8 & & \\
\hline College or more & 309 & 114 & 36.9 & & \\
\hline Occupation & & & & 35.549 & 0.000 \\
\hline Jobless & 45 & 33 & 73.3 & & \\
\hline Student & 323 & 94 & 29.1 & & \\
\hline Technician & 27 & 12 & 44.4 & & \\
\hline Clerical staff/worker & 159 & 62 & 40.0 & & \\
\hline Average monthly income & & & & 0.455 & 0.797 \\
\hline$<1000$ CNY & 204 & 75 & 36.8 & & \\
\hline $1000 \sim 4000 \mathrm{CNY}$ & 318 & 110 & 34.6 & & \\
\hline$>4000 \mathrm{CNY}$ & 166 & 62 & 37.3 & & \\
\hline Migration status & & & & 0.000 & 0.000 \\
\hline Non-migrant & 242 & 131 & 54.1 & & \\
\hline Migrant & 446 & 116 & 26.0 & & \\
\hline
\end{tabular}

level observed among women without restrictions in the same region [6]. The lower rate of PAC services utilization could be due to two evident variations between other studies and the current one. First, the present data were obtained from adolescents and young women. Women are initiating their sexual maturity earlier than ever and becoming sexual active prior to marriage due to the dramatic social changes in China in the past decade [8]. However, there is a lack of education on sex and reproductive knowledge in the traditional education system of China, leading to misconceptions about contraception and family planning counseling, especially compared to their western counterparts [8]. In addition, misled by deceptive advertising claiming painless abortion, Chinese young women, especially adolescents, no longer take the matter seriously, as if abortion was safe, affordable and with no impact on work. Therefore, these factors have helped to discourage adolescents and young women from seeking PAC. Second, the current provision of PAC in China does not address young people's concerns and needs. Young women, especially adolescents are often implicitly or explicitly blamed for their use of

Table 3 Variations in the use of PAC services by reproductive history

\begin{tabular}{|c|c|c|c|c|c|}
\hline \multirow{2}{*}{$\begin{array}{l}\text { Reproductive } \\
\text { history }\end{array}$} & \multirow[t]{2}{*}{ Total } & \multicolumn{2}{|c|}{ Use of PAC services } & \multirow[t]{2}{*}{$x^{2}$} & \multirow[t]{2}{*}{$P$} \\
\hline & & Frequency & Percentage(\%) & & \\
\hline \multicolumn{4}{|l|}{ Parity } & \multirow[t]{4}{*}{0.639} & \multirow[t]{4}{*}{0.727} \\
\hline 0 & 205 & 69 & 33.7 & & \\
\hline 1 & 233 & 86 & 36.9 & & \\
\hline$\geq 2$ & 250 & 92 & 36.8 & & \\
\hline \multicolumn{4}{|c|}{ Previous induced abortion } & \multirow[t]{3}{*}{0.937} & \multirow[t]{3}{*}{0.490} \\
\hline Yes & 350 & 125 & 35.7 & & \\
\hline No & 338 & 122 & 36.1 & & \\
\hline \multicolumn{4}{|c|}{ Number of living children } & \multirow[t]{3}{*}{0.465} & \multirow[t]{3}{*}{0.254} \\
\hline 0 & 419 & 155 & 37.0 & & \\
\hline 1 & 269 & 92 & 34.2 & & \\
\hline
\end{tabular}


Table 4 Variations in the use of PAC services by contraceptive practices

\begin{tabular}{|c|c|c|c|c|c|}
\hline \multirow[t]{2}{*}{ Contraceptive practices } & \multirow[t]{2}{*}{ Total } & \multicolumn{2}{|c|}{ PAC services utilization } & \multirow[t]{2}{*}{$x^{2}$} & \multirow[t]{2}{*}{$P$} \\
\hline & & Frequency & Percentage(\%) & & \\
\hline \multicolumn{4}{|c|}{ Knowledge on how soon fertility returns and could get pregnant again } & 1.104 & 0.576 \\
\hline Within $10 \sim 14$ days & 212 & 80 & 37.7 & & \\
\hline After $3 \sim 4$ weeks & 216 & 80 & 37.0 & & \\
\hline Don't know & 260 & 87 & 33.5 & & \\
\hline \multicolumn{4}{|l|}{ Any uptake of contraception } & 1.098 & 0.578 \\
\hline Yes & 283 & 96 & 33.9 & & \\
\hline No & 341 & 129 & 37.8 & & \\
\hline Missing & 64 & 22 & 34.3 & & \\
\hline \multicolumn{6}{|c|}{ Contraceptive use (multiple responses allowed) } \\
\hline None & 259 & 92 & 35.5 & 0.935 & 0.469 \\
\hline Traditional methods & 138 & 51 & 36.9 & 0.767 & 0.423 \\
\hline Oral contraceptives & 282 & 95 & 33.7 & 0.333 & 0.177 \\
\hline Male condoms & 357 & 129 & 36.1 & 0.937 & 0.479 \\
\hline
\end{tabular}

Traditional methods: rhythm, lactational amenorrhea, and withdrawal

abortion or family planning counseling. Moreover, globally, providers in PAC services have demonstrated a judgemental stance towards young people in counseling [9]. Specific attitudes and skills are not explicitly fostered. Such approaches have prevented them from seeking post-abortion counseling.
The findings of this study showed that being a student was significantly less likely to use PAC services compared to their jobless counterparts. This was consistent with the concept that women's empowerment and autonomy play a significant role in the process of seeking PAC [10]. Normally females in China aged 18 or below

Table $\mathbf{5}$ Variations in the use of PAC services by social factors

\begin{tabular}{|c|c|c|c|c|c|}
\hline \multirow[t]{2}{*}{ Variables } & \multirow[t]{2}{*}{ Total } & \multicolumn{2}{|c|}{ PAC services utilization } & \multirow[t]{2}{*}{$x^{2}$} & \multirow[t]{2}{*}{$\mathbf{P}$} \\
\hline & & Frequency & Percentage(\%) & & \\
\hline \multicolumn{2}{|l|}{ Having a feeling of stigma } & & & 177.1 & 0.000 \\
\hline Yes & 345 & 73 & 21.1 & & \\
\hline No & 228 & 160 & 70.2 & & \\
\hline Uncertain & 115 & 14 & 12.2 & & \\
\hline \multicolumn{3}{|c|}{ Spouses'/partners' attitudes on contraceptive use } & & 5.012 & 0.082 \\
\hline Approve & 260 & 107 & 41.2 & & \\
\hline Disapprove & 244 & 80 & 32.8 & & \\
\hline Uncertain & 184 & 60 & 32.6 & & \\
\hline \multicolumn{2}{|c|}{ Person responsible for PAC utilization } & & & 0.096 & 0.953 \\
\hline Spouse/partner/Parents & 235 & 86 & 36.6 & & \\
\hline Women herself & 223 & 80 & 35.9 & & \\
\hline Both & 230 & 81 & 35.2 & & \\
\hline \multicolumn{3}{|c|}{ Concerns about side-effects of contraceptives } & & 0.102 & 0.751 \\
\hline Yes & 351 & 124 & 35.3 & & \\
\hline No & 337 & 123 & 36.4 & & \\
\hline \multicolumn{2}{|c|}{ Negative attitudes towards PAC services } & & & 0.557 & 0.757 \\
\hline Yes & 240 & 82 & 34.2 & & \\
\hline No & 227 & 85 & 37.4 & & \\
\hline Uncertain & 221 & 80 & 36.2 & & \\
\hline
\end{tabular}


Table 6 Odds ratios from multivariate logistic regression examining factors associated with PAC utilization among adolescents and young women in Guangzhou, China

\begin{tabular}{lllll}
\hline Covariates & OR & SE & 95\% CI \\
\hline Occupation & & & & \\
Jobless & - & - & - & $0.129 \sim 0.453$ \\
Student & 0.308 & 0.231 & $0.289 \sim 0.961$ & - \\
Technician & 0.621 & 0.567 & $0.059 \sim 0.326$ \\
Clerical staff/worker & 0.396 & 0.127 & $0.116 \sim 0.627$ \\
Self-employed & 0.215 & 0.313 & & 0.551 \\
Migration status & & & - & 0.067 \\
Non-migrant & - & - & $0.137 \sim 0.620$ \\
Migrant & 0.409 & 0.094 & & - \\
Having a feeling of stigma & & & $0.104 \sim 0.378$ \\
Yes & 0.296 & 0.225 & - & 0.000 \\
No & - & - & $0.009 \sim 0.413$ \\
Uncertain & 0.608 & 0.129 & 0.000 \\
\hline
\end{tabular}

should still be receiving an education and the proportion of female students receiving college education is increasing. In comparison with their peers with formal or informal jobs, the majority of them are dependent on their parents for tuition and monthly pocket money. This finding proved some level of incompetency on the part of this group and their weak social support networks. Interestingly, in this case, we found that $92.8 \%$ of students were receiving college education. However, a higher level of education did not appear to enhance their possibility of seeking PAC, which was inconsistent with previous reports that women with higher educational level were more likely to seek PAC $[11,12]$. The gap of reproductive and sexual education in college education system between China and other countries may partially explain this paradox. This outcome also implied that college students were already involved in sexual activities and were at risk of subsequent repeat induced abortions. Further research on class year of students (first year students vs. second year and higher class year students) and college major (social sciences and humanities vs. natural sciences) may be helpful to explore possible barriers to PAC services utilization. The finding suggests that local governments need to strengthen the popularization of sexual knowledge and promote sexual health education in universities. Furthermore, a substantial proportion (86.7\%) of jobless women was married in this study, this may point to their good awareness of reproduction and contraception. A previous study has found that married women were more likely to utilize PAC compared to unmarried women [13]. This evidence, combined with the above explanations, is therefore likely to put students at a greater risk of not seeking PAC compared with jobless women, despite the financial constrains noted in both groups.

Our study echoes other studies that immigrant women were significantly less likely to use PAC services compared to their native counterparts [6]. Only a quarter received PAC services, suggesting limited or denial of access to family planning counseling. Immigrants in our study refer to the individuals who do not have a permanent resident certificate and have been living in Guangzhou for over one month. They were reluctant to seek PAC probably due to their lacking of medical insurance in the host cities. Because the payment system of medical expenses is based on a household registration system, immigrants have much less reimbursement than their natives. Although PAC is free of charge, contraceptives, particularly long-acting reversible contraceptives are not free of charge. Unintended pregnancies will continue to occur due to their lack of counseling or non-use of contraceptives. Underutilization of PAC services among migrant women compared to native women suggests the need for policies targeting migrant women who often face unmet family planning needs. This could include the integration of migrant women into the welfare structures in their host cities.

Another key finding of this paper is that women who had a feeling of stigma were significantly less likely to use PAC services compared to those who did not have such a feeling. This is consistent with findings in other qualitative studies assessing women's abortion experiences [14]. Women experiencing stigmatized abortion views may be misled by the perception that they are violating social norms, such as women's expected role as mothers. This view may contribute to their delays in 
pursuing an abortion as well as seeking PAC. Additionally, young women, especially teenagers may refuse to be presented at PAC services in order to maintain secrecy to reduce the number of people who become aware that they had an abortion to forestall stigmatization. Efforts should be made to address community-level attitudes and beliefs on abortion as well as reinforce the role of PAC in helping women better reproductive health. However, these interventions should be cautious of not further stigmatizing women. Further research is needed to explore the role of stigma-related barriers in determining the utilization of PAC services among adolescents and young women in China.

This study has some limitations. First, the generalizability of this study would be limited as we only conducted the study in public hospitals. We might have missed out the proportion of women who seek PAC in private clinics. Second, reporting bias may exist in the survey although we used anonymous self-administered questionnaire. Given the sensibility of the topic, adolescents and young women might provide responses they feel socially desirable. Third, we did not ask women to list all sources of stigma.

\section{Conclusion}

The uptake of PAC services remains low among adolescents and young women in the study setting where the provision of youth-friendly services in public hospitals was being experimented. Underutilization of the services occurs among students, immigrants, and those who had a feeling of stigma. The findings suggest the need for policies and programs to not only strengthen the provision of youth-friendly services but also promote education about both family planning and abortion services among disadvantaged subgroups of women.

\section{Abbreviation}

PAC: Post-abortion care I

\section{Acknowledgements}

We acknowledge the contributions of Min Liang who was involved in the original design of the study.

\section{Authors' contributions}

YD.W. and RB.X. conceived the study, the methodology was developed by RB.X. and Y.L., YD.W. and JZ.L. carried out the interviews. Y.L. and RB.X. analyzed the interviews. YD.W. wrote the first draft of the manuscript and all other authors edited the manuscript. All authors read and approved the final manuscript.

\section{Funding}

Not applicable.

\section{Availability of data and materials}

The datasets used and/or analyzed during the current study are available from the corresponding author on reasonable request.

\section{Declarations}

\section{Ethics approval and consent to participate}

Ethical approval was obtained from the Research Ethics Board of Southern Medical University on 12th January 2018. Participants were provided with a participant information sheet and asked to sign a consent form prior to the interviews being undertaken. For participant under 18 years old, written informed consent was obtained from their parents/guardians while the participants provided written assent. All protocols are carried out in accordance with relevant guidelines and regulations.

\section{Consent for publication}

Not applicable.

\section{Competing interests}

The authors declare that they have no competing interests.

Received: 26 January 2021 Accepted: 9 March 2021

Published online: 28 May 2021

\section{References}

1. Che Y, Dusabe-Richards E, Wu S, Jiang Y, Dong X, Li J, et al. A qualitative exploration of perceptions and experiences of contraceptive use, abortion and post-abortion family planning services (PAFP) in three provinces in China. BMC Womens Health. 2017;17(1):113. https://doi.org/10.1186/s12905017-0458-z.

2. ESHRE Capri Workshop Group. Induced abortion. Hum Reprod. 2017;32(6): 1160-9. https://doi.org/10.1093/humrep/dex071.

3. Ushie BA, Izugbara CO, Mutua MM, Kabiru CW. Timing of abortion among adolescent and young women presenting for post-abortion care in Kenya: a cross-sectional analysis of nationally-representative data. BMC Womens Health. 2018;18(1):41. https://doi.org/10.1186/s12905-018-0521-4.

4. Dickens BM. Post-abortion care: ethical and legal duties. Int J Gynaecol Obstet. 2019:14:273-8

5. The Central Committee of the Communist Party of China Medium and Long Period Development Program for Young People (2016-2025). Available online: http://www.gov.cn/xinwen/2017-04/13/content_5185555.().

6. Wang $H$, Liu Y, Xiong R. Factors associated with seeking post-abortion care among women in Guangzhou, China. BMC Womens Health. 2020;20(1):120. https://doi.org/10.1186/s12905-020-00980-0.

7. Tang L, Wu S, Li J, Wang K, Xu J, Temmerman M, Zhang WH, INPAC Consortium. Post-abortion family planning counselling practice among abortion service providers in China: a nationwide cross-sectional study. Eur Contracept Reprod Health Care. 2017;22(1):24-9. https://doi.org/10.1080/13 625187.2016 .1255939$.

8. Liu J, Wu S, Xu J, Temmerman M, Zhang WH, INPAC Group. Is repeat abortion a public health problem among Chinese adolescents? A crosssectional survey in 30 provinces. Int J Environ Res Public Health. 2019;16(5): 794. https://doi.org/10.3390/ijerph16050794.

9. Jiang H, Xu J, Richards E, Qian X, Zhang W, Hu L, Wu S, Tolhurst R, INPAC Consortium. Opportunities, challenges and systems requirements for developing post-abortion family planning services: perceptions of service stakeholders in China. PLoS One. 2017;12(10):e0186555. https://doi.org/10.13 71/journal.pone.0186555.

10. Gelaye AA, Taye KN, Mekonen T, Gelaye AA. Magnitude and risk factors of abortion among regular female students in Wolaita Sodo University, Ethiopia. BMC Womens Health. 2014;14:50.

11. Mutua MM, Maina BW, Achia TO, Izugbara CO, Mutua MM. Factors associated with delays in seeking post abortion care among women in Kenya. BMC Pregnancy Childbirth. 2015;15(1):241. https://doi.org/10.1186/ s12884-015-0660-7.

12. Kabiru CW, Ushie BA, Mutua MM, Izugbara CO, Kabiru CW. Previous induced abortion among young women seeking abortion-related care in Kenya: a cross-sectional analysis. BMC Pregnancy Childbirth. 2016;16(1):104. https:// doi.org/10.1186/s12884-016-0894-Z

13. Zhu JL, Zhang WH, Cheng Y, Xu J, Xu X, Gibson D, Støvring H, Claeys $P$, Temmerman $\mathrm{M}$. Impact of post-abortion family planning services on contraceptive use and abortion rate among young women in China: a cluster randomised trial. Eur J Contracept Reprod Health Care. 2009:14(1): 46-54. https://doi.org/10.1080/13625180802512994. 
14. Gelman A, Rosenfeld EA, Nikolajski C, Freedman LR, Steinberg JR, Borrero S. Abortion stigma among low-income women obtaining abortions in western Pennsylvania: a qualitative assessment. Perspect Sex Reprod Health. 2017:49(1):29-36. https://doi.org/10.1363/psrh.12014.

\section{Publisher's Note}

Springer Nature remains neutral with regard to jurisdictional claims in published maps and institutional affiliations.

Ready to submit your research? Choose BMC and benefit from:

- fast, convenient online submission

- thorough peer review by experienced researchers in your field

- rapid publication on acceptance

- support for research data, including large and complex data types

- gold Open Access which fosters wider collaboration and increased citations

- maximum visibility for your research: over $100 \mathrm{M}$ website views per year

At $\mathrm{BMC}$, research is always in progress.

Learn more biomedcentral.com/submissions 